\title{
Adenosine Receptors Mediate Synergistic Stimulation of Glucose Uptake and Transport by Insulin and by Contractions in Rat Skeletal Muscle
}

\author{
L. Vergauwen, ${ }^{*}$ P. Hespel, * and E. A. Richter* \\ *Exercise Physiology Laboratory, Faculty of Physical Education and Physiotherapy, Catholic University of Leuven, B-3001 Leuven, \\ Belgium and ${ }^{\ddagger}$ August Krogh Institute, University of Copenhagen, DK-2100 Copenhagen, Denmark
}

\begin{abstract}
The role of adenosine receptors in the regulation of muscle glucose uptake by insulin and contractions was studied in isolated rat hindquarters that were perfused with a standard medium containing no insulin or a submaximal concentration of $100 \mu \mathrm{U} / \mathrm{ml}$. Adenosine receptor antagonism was induced by caffeine or 8-cyclopentyl-1,3-dipropylxantine (CPDPX). Glucose uptake and transport were measured before and during 30 min of electrically induced muscle contractions. Caffeine nor CPDPX affected glucose uptake in resting hindquarters. In contrast, the contraction-induced increase in muscle glucose uptake was inhibited by $\mathbf{3 0}-\mathbf{5 0} \%$ by caffeine, as well as by CPDPX, resulting in a $20-25 \%$ decrease in the absolute rate of glucose uptake during contractions, compared with control values. This inhibition was independent of the rate of perfusate flow and only occurred in hindquarters perfused with insulin added to the medium. Thus, adenosine receptor antagonism inhibited glucose uptake during simultaneous exposure to insulin and contractions only. Accordingly, caffeine inhibited 3-Omethylglucose uptake during contractions only in oxidative muscle fibers that are characterized by a high sensitivity to insulin. In conclusion, the present data demonstrate A1 receptors to regulate insulin-mediated glucose transport in contracting skeletal muscle. The findings provide evidence that stimulation of sarcolemmic adenosine receptors during contractions is involved in the synergistic stimulation of muscle glucose transport by insulin and by contractions. (J. Clin. Invest. 1994. 93:974-981.) Key words: skeletal muscle • glucose transport • insulin • adenosine receptors $\bullet$ contractions
\end{abstract}

\section{Introduction}

Skeletal muscle is a major site of body glucose disposal (1). Under basal conditions, the rate of skeletal muscle glucose uptake is low. Glucose uptake rate, however, markedly exceeds basal values when muscle contracts (2), and/or when muscle is exposed to insulin (3). Insulin and contractions have independently shown to stimulate membrane glucose transport via increasing the number of active sarcolemmic glucose transport-

Address correspondence to P. Hespel, Ph.D., Faculty of Physical Education and Physiotherapy, Exercise Physiology Laboratory, Tervuursevest 101 , B-3001 Heverlee, Belgium.

Received for publication 1 July 1993 and in revised form 26 October 1993.

J. Clin. Invest.

(C) The American Society for Clinical Investigation, Inc.

0021-9738/94/03/0974/08 \$2.00

Volume 93, March 1994, 974-981 ers (4-6), and possibly via enhancing the intrinsic activity of the transporters (7-9).

When muscle is simultaneously exposed to insulin and contractions, glucose uptake in most studies (10-16) is elevated to values exceeding the ones observed when muscle is stimulated by either stimulus alone. The total increase in muscle glucose uptake occurring in response to simultaneous stimulation by insulin and contractions has been demonstrated to be fully additive (11) or even synergistically additive (12-16). The molecular mechanism underlying this interactive effect of insulin and contractions may include translocation and/or activation of glucose transporters from separate pools (17), recruitment of distinct transporter isoforms, and / or different cellular signaling mechanisms leading to activation of the transport system (18). The precise nature of interaction of insulin and contractions in regulating glucose transport in muscle during contractions remains, however, speculative.

Adenosine receptors may be important in modulating the effects of insulin on muscle glucose transport. On the one hand, adenosine receptors have been demonstrated to modulate insulin-stimulated glucose transport and uptake in different insulin-sensitive tissues, including skeletal muscle. Indeed, decreasing extracellular adenosine concentration in resting muscle by addition of adenosine deaminase has been demonstrated to stimulate glucose transport (19). A similar effect of adenosine receptor antagonism by either 8-cyclopentyl-1,3-dipropylxanthine (CPDPX) ${ }^{1}$ or 8-phenyltheophylline was observed on 2deoxy- $\left[{ }^{3} \mathrm{H}\right]$ glucose transport or phosphorylation (20). On the other hand, it is well known that muscle adenosine production and release are markedly enhanced during contractions, particularly in slow oxidative muscle fibers $(21,22)$, probably leading to adenosine receptor-mediated vasodilation of local vascular beds (21). Furthermore, adenosine has been demonstrated to enhance insulin-stimulated glucose uptake and transport in adipocytes (23-25) and in myocardium $(26,27)$. Thus, adenosine receptors might fulfill a similar role in regulating insulinmediated glucose uptake in muscle during contractions.

The aim of the present study was, therefore, to examine the role of adenosine receptors in regulating glucose uptake and transport in contracting skeletal muscle. The data for the first time demonstrate that adenosine receptor stimulation enhances insulin-mediated glucose uptake and transport in contracting but not in resting skeletal muscle. Moreover, this action of adenosine receptors is shown to be largely responsible for the presently and previously observed "synergistic" stimulation of muscle glucose uptake and transport via insulin and contractions in insulin-sensitive muscle fibers.

1. Abbreviations used in this paper: $\mathrm{A} 1$ receptor, adenosine receptor of the Al subtype; CPA, $N^{6}$-cyclopentyladenosine; CPDPX, 8-cyclopentyl-1,3-dipropylxanthine. 


\section{Methods}

Animals. Male Wistar rats weighing 200-250 g were used in this study. Rats were purchased from the laboratory animal breeding center from the Catholic University of Leuven. Rats were maintained on a constant light/dark cycle and received normal rat chow ad libitum until the morning the experiments were carried out.

Experimental procedures. The rats were anesthetized by an intraperitoneal injection of pentobarbital sodium $(5 \mathrm{mg} / 100 \mathrm{~g}$ body $\mathrm{wt})$ and prepared surgically for hindquarter perfusion, as previously described (28-30). Before insertion of the perfusion catheters, the rat was heparinized with $250 \mathrm{IU}$ of heparin in the inferior vena cava. The rat was killed with an intracardial injection of pentobarbital sodium immediately before being placed in the perfusion cabinet.

The initial perfusate $(150-230 \mathrm{ml})$ consisted of Krebs-Henseleit solution, 1-3-d-old washed bovine erythrocytes at a $30 \%$ hematocrit, 5\% BSA (Cohn fraction V; Sigma Immunochemicals, St Louis, MO), 6 $\mathrm{mM}$ glucose, $0.15 \mathrm{mM}$ pyruvate, and $0.3-0.5 \mathrm{mM}$ lactate originating from the erythrocytes. During the hindlimb perfusion experiments, the arterial perfusate was continuously gassed with a mixture of $62 \%$ nitrogen, $35 \%$ oxygen, and $3 \%$ carbon dioxide, which at rest and during electrical stimulation, yielded a mean arterial $\mathrm{pH}$ value of 7.36 (range $=7.26-7.46 ; n=139)$ and 7.34 ( range $=7.25-7.44 ; n=122), \mathrm{PCO}_{2}$ of $37 \mathrm{mmHg}$ (range $=29-44 \mathrm{mmHg} ; n=139$ ) and $39 \mathrm{mmHg}$ (range $=30-46 \mathrm{mmHg} ; n=122$ ), and $\mathrm{PO}_{2}$ of $224 \mathrm{mmHg}$ (range $=203-255$ $\mathrm{mmHg} ; n=139$ ) and $157 \mathrm{mmHg}$ ( range $=101-239 \mathrm{mmHg} n=122$ ), respectively. To prevent it from decreasing in the course of hindlimb perfusion, arterial glucose concentration was clamped at $6 \mathrm{mM}$ by a continuous infusion of a $40 \%$ glucose solution into the perfusate reservoir using a microinfusion pump (model 11; Harvard Apparatus Co., Inc., South Natick, MA), the speed of which was adjusted to the estimated rate of glucose uptake by the hindquarter.

The first $25 \mathrm{ml}$ of perfusate that passed through the hindquarter were discarded, whereupon the perfusate was recirculated at a flow of $12.5 \mathrm{ml} / \mathrm{min}$. After a 20-min equilibration period, muscle samples of the left gastrocnemius-soleus-plantaris muscle group were taken. The medial superficial part of the gastrocnemius muscle, consisting primarily of fast-twitch white fibers, the soleus muscle, which contains primarily slow-twitch red fibers and a portion of the deep part of the medial head of the gastrocnemius muscle, which contains primarily fast-twitch red fibers ( 31 ) were cut out, trimmed of connective tissue and visible blood, and freeze clamped with aluminum clamps cooled in liquid $\mathrm{N}_{2}$. Subsequently, the common iliac vessels supplying the biopsied leg were tied off, and a clamp was fixed tightly around the proximal part of the leg. From that moment, different protocols were used in different subsamples of rats.

In protocol 1, perfusion flow to the right hindlimb was reduced to 9 $\mathrm{ml} / \mathrm{min}$, which resulted in comparable perfusion pressures ( mean $=55$ $\mathrm{mmHg}$; range $=42-79 \mathrm{mmHg} ; n=139)$ as for bilateral perfusion at a flow of $12.5 \mathrm{ml} / \mathrm{min}$ (mean $=54 \mathrm{mmHg}$; range $=40-78 \mathrm{mmHg} ; n$ = 139). The right lower leg was then immobilized by a pin under the patella tendon, which was fixed onto the perfusion platform, and a hook pin around the Achilles' tendon. The latter was connected to an isometric muscle tension transducer. The immobilized hindlimb was then allowed to rest for an additional $5 \mathrm{~min}$, after which perfusate samples were taken from the venous and the arterial tubing for baseline determinations. Immediately after, a hook electrode was placed around the uncut sciatic nerve and connected to a locally constructed impulse generator. The resting length of the gastrocnemius-soleus-plantaris muscle group was adjusted to obtain maximum active tension upon stimulation, whereupon the electrical stimulation period was started. Perfusate flow was increased simultaneously from 9 to $15 \mathrm{ml} / \mathrm{min}$, resulting in a mean perfusion pressure of $81 \mathrm{mmHg}$ (range $=57-110$ $\mathrm{mmHg} ; n=122$ ) during stimulation. The muscles were made to contract isometrically by stimulating the sciatic nerve electrically with supramaximal $(20-30 \mathrm{~V})$ trains of $50 \mathrm{~ms}$ at $100 \mathrm{~Hz}$, each impulse in the train lasting for $1 \mathrm{~ms}$. The trains were delivered at a rate of $20 / \mathrm{min}$ for $30 \mathrm{~min}$. During stimulation, tension developed by the gastrocnemius- soleus-plantaris muscle group was measured by the isometric muscle tension transducer and recorded by a pen writer (Kipp \& Zonen, Delft, The Netherlands). At the end of the electrical stimulation period, perfusate flow through the hindlimb was stopped and muscle samples were rapidly dissected, as described above. During the 30 -min stimulation period, arterial and venous perfusate samples were taken after 5,15 , and $25 \mathrm{~min}$.

In a subsample of hindquarters perfused according to protocol 1 , muscle membrane glucose transport and extracellular space during the last $5 \mathrm{~min}$ of the 30 -min stimulation period were measured using a slightly modified protocol. $10 \mu \mathrm{Ci}$ of $3-O-\left[{ }^{14} \mathrm{C}\right]$ methyl-D-glucose (specific activity $=250-360 \mathrm{mCi} / \mathrm{mmol}$; New England Nuclear, Boston, MA) together with $25 \mu \mathrm{Ci}$ of $\left[{ }^{3} \mathrm{H}\right]$ mannitol (specific activity $=15-30$ $\mathrm{Ci} / \mathrm{mmol}$; New England Nuclear) were simultaneously added to the perfusate reservoir. Recirculation of perfusate was stopped to maintain a constant specific activity for glucose into the arterial perfusate during the period of glucose transport measurement. After the hindlimb was exposed to the isotopes for exactly $5 \mathrm{~min}$, perfusate flow was stopped and muscles were sampled, as described above.

In protocol 1, the right hindlimb was perfused at a flow of $9 \mathrm{ml} / \mathrm{min}$ at rest and at $15 \mathrm{ml} / \mathrm{min}$ during contractions. To determine whether the effect of adenosine receptor antagonism on glucose uptake in contracting skeletal muscle is to be attributed to contractions per se, to flow per se, or to a combination of both factors, two other protocols were used. In protocol 2, perfusate flow was set at $15 \mathrm{ml} / \mathrm{min}$ in resting hindlimbs. This flow was maintained during electrical stimulation. Similar to protocol 1 type perfusions, perfusate samples were taken after 5,15 , and $25 \mathrm{~min}$ of electrical stimulation. In protocol 3, at the end of the resting period, perfusate flow was increased from 9 to 15 $\mathrm{ml} / \mathrm{min}$ without induction of muscle contractions. Perfusate samples were taken after $5 \mathrm{~min}$ of perfusion at this elevated flow, whereafter the experiment was stopped.

Experimental conditions. All experiments were performed according to the above described standard procedures. Different experimental conditions were created by adding caffeine (Aldrich, Steinheim, West Germany), human monocomponent insulin (Novo Nordisk, Bagsværd, Denmark), CPDPX (Research Biochemicals Inc., Natick, MA) and $N^{6}$-cyclopentyladenosine (CPA) (Research Biochemicals Incorporate) to the arterial perfusate. All perfusion experiments designed for mutual comparisons were carried out in a randomized order.

For studying the effects of unselective adenosine receptor antagonism, caffeine was added to the initial arterial perfusate in a concentration of $77 \mu \mathrm{M}$ in the presence of 0 or $100 \mu \mathrm{U}$ insulin $/ \mathrm{ml}$ of perfusate plasma. In further experiments, the effects of selective antagonism and agonism of adenosine receptors of the Al subtype ( $\mathrm{A} 1$ receptors) were investigated at an arterial insulin level of $100 \mu \mathrm{U} / \mathrm{ml}$. For this purpose, CPDPX, an Al receptor antagonist (32), was added to the perfusate reservoir in a concentration of $77 \mu \mathrm{mol} /$ liter of perfusate plasma. Since CPDPX was to be dissolved in ethanol because of its poor solubility in water, a similar volume of ethanol $(250 \mu \mathrm{l})$ was added to control perfusate media. CPA, an A1-specific adenosine receptor agonist, was dissolved in $20 \mu \mathrm{l}$ ethanol and added to the perfusate resulting in a concentration of $1 \mu \mathrm{M}$. In the corresponding control group, $20 \mu \mathrm{l}$ ethanol was added to the perfusion mix.

Analyses, calculations, and statistics. All perfusate samples were analyzed for glucose and lactate concentrations in duplicate or triplicate within $1 \mathrm{~h}$, using a dual channel glucose-lactate analyzer (type 2300 STAT; Yellow Springs Instruments Co., Yellow Springs, OH ). At rest and after $15 \mathrm{~min}$ of electrical stimulation, hemoglobin concentration, oxygen saturation of hemoglobin, $\mathrm{Po}_{2}, \mathrm{PCO}_{2}$, and pH were determined in perfusate sampled anaerobically, using an ABL 510 acid base laboratory (Radiometer, Copenhagen, Denmark).

Muscle samples were stored at $-80^{\circ} \mathrm{C}$ until analyzed. cAMP in muscle was measured in perchloric acid extracts by a binding protein assay system, purchased from Amersham Denmark (Birkerød, Denmark).

Uptake of $\left[{ }^{14} \mathrm{C}\right] 3-O$-methylglucose in muscles was determined in perchloric acid extracts and corrected for label in the extracellular 
space determined by the ${ }^{3} \mathrm{H}$ counts for mannitol. Radioactivity was measured in a liquid scintillation counter (Model 2000 CA; Packard Instruments Co., Downers Grove, IL). From the intracellular accumulation of ${ }^{14} \mathrm{C}$-labeled 3-O-methylglucose, rates of glucose transport were calculated using a "specific activity of glucose" determined by the glucose concentration in the cell-free perfusate and the plasma 3-O-methylglucose counts. The duration of exposure to 3-O-methylglucose was kept short $(5 \mathrm{~min})$ to prevent accumulation of 3-O-methylglucose in intramuscular water of $>30 \%$ of extracellular water concentration. Preliminary experiments showed that uptake of 3-O-methylglucose is linear with time under these conditions.

Rates of glucose and oxygen uptake by the hindquarter, as well as lactate release, were calculated by multiplying the measured arteriovenous concentration differences by the flow rate, and were expressed per gram of perfused muscle per hour. Perfusate flow rate was measured using time collections of the venous effluent. Perfused muscle mass was considered to be $8.3 \%$ of body weight ( 30 ).

Statistical evaluation of the data was done by unpaired $t$ test (Statistical Analysis System, $t$ test procedure) or two-way ANOVA (Statistical Analysis System, General Linear Model procedures) where appropriate. Data obtained in resting hindquarters were analyzed separately from data obtained in electrically stimulated hindquarters. Data are presented as mean $\pm \mathrm{SE} . P<0.05$ was chosen as the criterion for acceptance of statistical significance.

\section{Results}

\section{Glucose uptake and transport}

Protocol 1. In resting hindquarters, neither caffeine nor CPDPX significantly affected glucose uptake in the presence $(100 \mu \mathrm{U} / \mathrm{ml}$ ) or in the absence of insulin (Figs. 1 and 2). In the absence of insulin, the increase in glucose uptake during contractions was unaffected by caffeine (Fig. 3). However, at a perfusate insulin concentration of $100 \mu \mathrm{U} / \mathrm{ml}$, both caffeine and CPDPX attenuated the increase in glucose uptake during contractions (Fig. 3). Thus, at the onset of electrically induced muscle contractions, the increase in muscle glucose uptake in hindquarters perfused with insulin was much smaller ( $P$ $<0.05)$ during adenosine receptor antagonism than under control conditions, resulting in lower rates $(P<0.05)$ of glu-

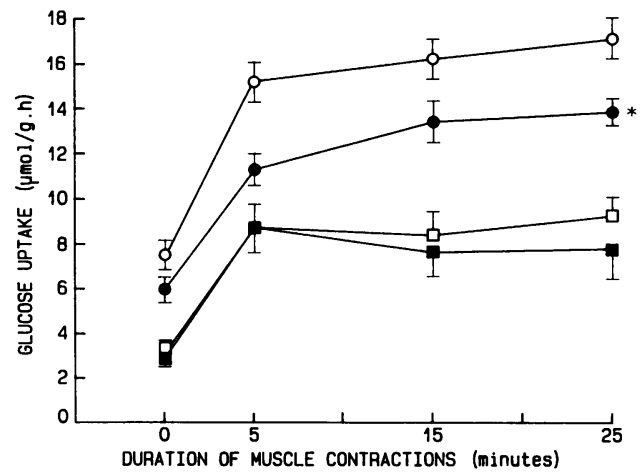

Figure 1. Effect of caffeine on glucose uptake in resting and contracting muscle. Values are mean $\pm \mathrm{SE}$ of 13-27 observations. Hindquarters were perfused in the absence ( $O$ and $\square$ ) and in the presence of $77 \mu \mathrm{M}$ caffeine ( $\bullet$ and $\square$ ) at 0 ( $\square$ and $\bullet$ ) and at $100 \mu \mathrm{U} / \mathrm{ml}$ insulin $(\mathrm{O}$ and $\bullet$ ). Contractions were induced by supramaximal stimulation of the sciatic nerve. Flow was $9 \mathrm{ml} / \mathrm{min}$ at rest and $15 \mathrm{ml} / \mathrm{min}$ during contractions. Glucose uptake was calculated as arteriovenous glucose concentration differences times the flow rate. See Methods for further details. ${ }^{*} P<0.05$ compared with corresponding control data during contractions.

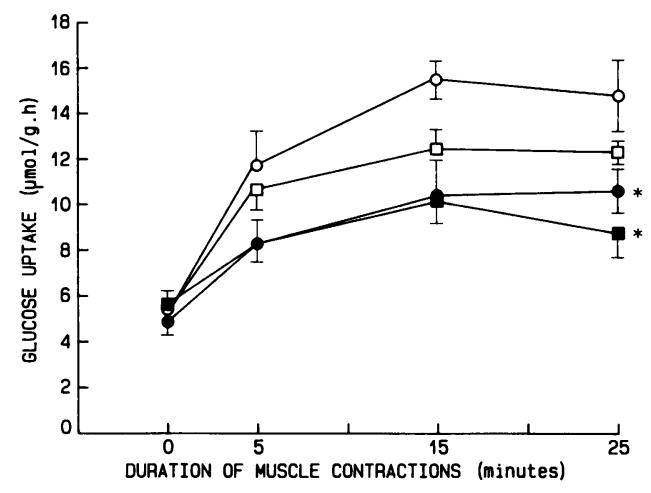

Figure 2. Effect of CPDPX on glucose uptake in resting and contracting muscle. Values are mean $\pm \mathrm{SE}$ of $8-11$ observations. Hindquarters were perfused at rest and during contractions with vehicle ( $\circ$ and $\square$ ) or $77 \mu \mathrm{M}$ CPDPX (• and $\square$ ) at an insulin concentration of $100 \mu \mathrm{U} / \mathrm{ml}$. Contractions were induced by supramaximal stimulation of the sciatic nerve. Perfusate flow at rest was either 9 ( $O$ and $\bullet$ ) or $15 \mathrm{ml} / \mathrm{min}$ ( $\square$ and $\square$ ). Perfusate flow during electrical stimulation was $15 \mathrm{ml} / \mathrm{min}$ in all groups. See Methods for further details. ${ }^{*} P$ $<0.05$ compared with corresponding control values during contractions.

cose uptake during the entire stimulation period (Figs. 1 and 2 ). The increase in glucose uptake from rest to $5 \mathrm{~min}$ of electrical stimulation averaged $+7.8 \pm 0.9$ and $+5.4 \pm 0.8 \mu \mathrm{mol} / \mathrm{g}$ per $\mathrm{h}$ in control and caffeine rats, respectively $(P<0.05)$. The increase in glucose uptake from rest to $15 \mathrm{~min}$ of electrical stimulation was on the average $+6.3 \pm 1.1$ and $+3.4 \pm 1.3 \mu \mathrm{mol} / \mathrm{g}$ per $\mathrm{h}$ in control and CPDPX perfused rats, respectively $(P$ $<0.05$ ).

The initial rate of muscle $\left[{ }^{14} \mathrm{C}\right] 3-O$-methylglucose uptake, measured during the last $5 \mathrm{~min}$ of the 30 -min stimulation period, was used as a measure of muscle membrane glucose trans-

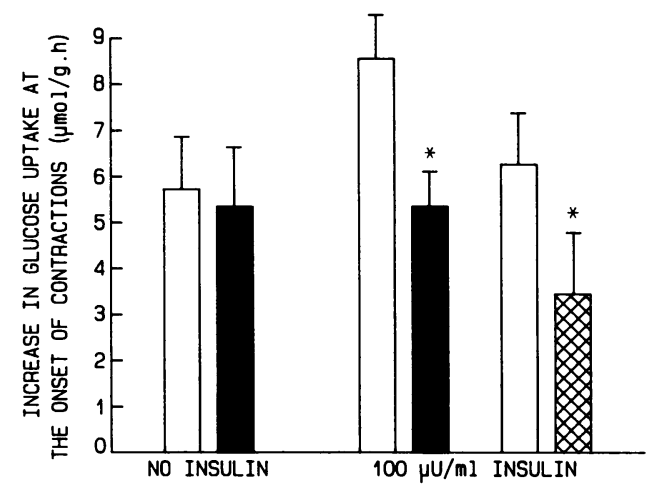

Figure 3. Effect of adenosine receptor antagonism on the increment in hindquarter glucose uptake from rest to contractions. Values are mean \pm SE of 9-27 observations. Adenosine receptor antagonism was induced by caffeine $(77 \mu \mathrm{M})$ or by CPDPX $(77 \mu \mathrm{M}) .0$ or $100 \mu \mathrm{U} / \mathrm{ml}$ insulin were added to the perfusate. Open, solid, and hatched bars represent data from control, caffeine, and CPDPX hindquarters, respectively. Contractions were induced by supramaximal stimulation of the sciatic nerve. Flow was $9 \mathrm{ml} / \mathrm{min}$ at rest and $15 \mathrm{ml} / \mathrm{min}$ during contractions. Increases were calculated as the differences between glucose uptake after $5 \mathrm{~min}$ of contractions minus resting glucose uptake for caffeine and CPDPX hindquarters, respectively. See Methods for further details. ${ }^{*} P<0.05$ compared with the corresponding control data. 


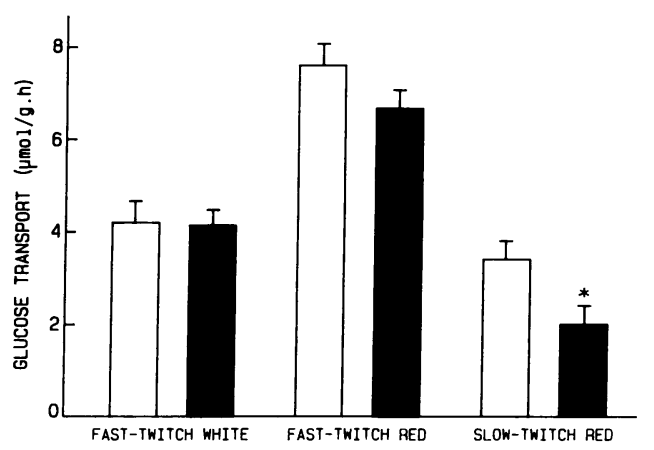

Figure 4. Effect of caffeine on the rate of glucose transport in contracting muscle. Values are mean $\pm S E$ of 12 observations. Glucose transport was measured in fast-twitch white, fast-twitch red, and slow-twitch red muscle fibers. Open bars, control data; solid bars, data from hindquarters perfused with $77 \mu \mathrm{M}$ caffeine. Muscle glucose transport was measured as the initial rate of $3-O-\left[{ }^{14} \mathrm{C}\right]$ methylglucose accumulation in muscle, corrected for label present in the extracellular space. See Methods for further details. ${ }^{*} P<0.05$ compared with corresponding control data.

port in hindquarters perfused with insulin. As shown in Fig. 4, muscle 3-O-methylglucose uptake was inhibited $(P<0.05)$ by caffeine in type I fibers (minus $42 \%$ ), but not significantly in type IIa or in type IIb fibers.

Recent experiments in our laboratory have shown that in the experimental conditions similar to the ones in protocol 1 , increasing perfusate flow from 9 to $15 \mathrm{ml} / \mathrm{min}$ in the presence of $100 \mu \mathrm{U} / \mathrm{ml}$ insulin, markedly increases the rate of glucose uptake by the resting hindquarter. ${ }^{2}$ Thus, the increase in hindlimb glucose uptake at the onset of electrical stimulation (Fig. 3 ) must have been produced by contractions per se, as well as by the concomitant increase in flow. Therefore, additional experiments were performed to investigate the specific effect of adenosine receptor antagonism on the flow-(protocol 2) and contraction-induced increase in muscle glucose uptake (protocol 3), respectively.

Protocol 2. In accordance with the observations in protocol 1, caffeine had no effect on glucose uptake in resting hindquarters. Hindquarter glucose uptake was on the average $5.2 \pm 0.4$ and $4.9 \pm 0.4 \mu \mathrm{mol} / \mathrm{g}$ per $\mathrm{h}$ in control $(n=29)$ and in caffeine conditions $(n=27)$, respectively, at a flow of $9 \mathrm{ml} /$ $\min$. When the flow of perfusate was increased from 9 to 15 $\mathrm{ml} / \mathrm{min}$, glucose uptake rate in resting hindquarters increased similarly in both groups $(+1.9 \pm 0.7$ and $+1.3 \pm 0.9 \mu \mathrm{mol} / \mathrm{g}$ per $h$ in control and in caffeine hindquarters, respectively) to a level of $7.1 \pm 0.7$ and $6.2 \pm 0.7 \mu \mathrm{mol} / \mathrm{g}$ per $\mathrm{h}$ after $5 \mathrm{~min}$ at the higher flow in control and caffeine hindquarters, respectively.

Protocol 3. In this protocol, hindquarters were perfused at a constant flow of $15 \mathrm{ml} / \mathrm{min}$, both at rest and during electrical stimulation. In line with the observations in protocol 1 , CPDPX was found to have no effect on glucose uptake in resting hindlimbs (Fig. 2). As demonstrated in Fig. 5, upon initiation of electrically induced muscle contractions hindquarter glucose uptake increased markedly more $(P<0.05)$ in control hindquarters $(+7.0 \pm 1.1 \mu \mathrm{mol} / \mathrm{g}$ per $\mathrm{h})$ than in hindquarters perfused with CPDPX $(+4.4 \pm 0.8 \mu \mathrm{mol} / \mathrm{g}$ per $\mathrm{h})$. At the end of

2. Hespel, P., L. Vergauwen, K. Vandenberghe, and E. A. Richter, manuscript submitted for publication.

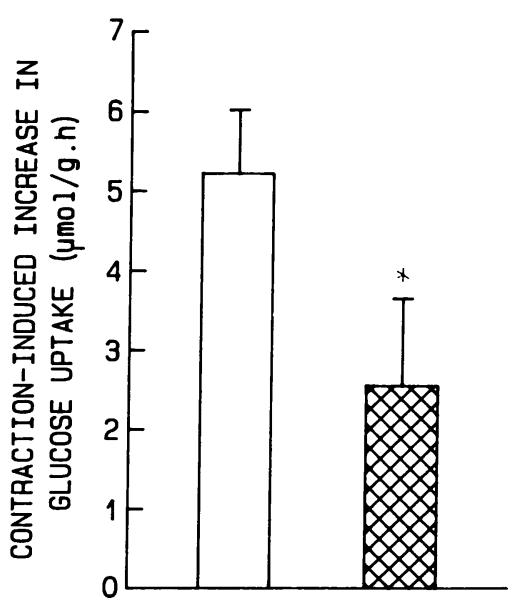

Figure 5. Effect of CPDPX on the contraction-induced increase in glucose uptake. Values are mean \pm SE of 9 or 12 observations. Hindquarters were perfused with vehicle (open bar) or with $77 \mu \mathrm{M}$ CPDPX (hatched bar) at a plasma insulin concentration of $100 \mu \mathrm{U} /$ $\mathrm{ml}$. The contraction-induced increase in glucose uptake was calculated by subtracting glucose uptake in resting hindlimb from glucose uptake after $5 \mathrm{~min}$ of contractions. Contractions were induced by supramaximal stimulation of the sciatic nerve. Perfusate flow in resting and contracting muscles was set at $15 \mathrm{ml} / \mathrm{min}$. See Methods for further details. ${ }^{*} P<0.05$ compared with control.

the 30-min stimulation period, compared with the control condition, glucose uptake was on the average $28 \%$ lower $(P<0.05)$ in hindquarters perfused with CPDPX (Fig. 2).

The effects of $\mathrm{A} 1$ receptor agonism were investigated according to the procedures of protocol 1. As shown in Table I, stimulation of $\mathrm{A} 1$ receptors by CPA at an insulin concentration of $100 \mu \mathrm{U} / \mathrm{ml}$ did affect glucose uptake neither at rest nor during contractions.

\section{Muscle cAMP concentrations}

The concentration of cAMP was measured only in muscle samples from hindlimbs perfused with insulin present in the medium. As shown in Table II, caffeine did alter the concentration of cAMP in any fiber type, neither at rest nor after $30 \mathrm{~min}$ of contractions.

\section{Oxygen uptake, muscle performance, and} perfusion pressure

Hindlimb oxygen uptake, muscle tension during electrical stimulation and perfusion pressures were altered neither by adenosine receptor antagonism (caffeine, CPDPX) nor agonism (CPA). Oxygen uptake averaged $24 \pm 0.4 \mu \mathrm{mol} / \mathrm{g}$ per $\mathrm{h}(n$ $=221$ ) in resting hindlimbs, increasing three- to fourfold to

Table I. Effect of AI Receptor Agonism by CPA on Glucose Uptake ( $\mu \mathrm{mol} / \mathrm{g}$ per h) in Resting and Contracting Muscle

\begin{tabular}{lcccc}
\hline & \multicolumn{5}{c}{ Duration of muscle contractions } \\
\cline { 2 - 5 } Group & 0 & 5 & $\min$ & 25 \\
\hline Control & $6.2 \pm 0.8$ & $12.5 \pm 1.0$ & $15.5 \pm 0.9$ & $15.9 \pm 0.5$ \\
CPA & $6.0 \pm 0.6$ & $13.6 \pm 0.9$ & $15.6 \pm 0.7$ & $17.0 \pm 0.9$
\end{tabular}

Values are mean \pm SE of 18-19 observations. Hindquarters were perfused with vehicle or CPA $(1 \mu \mathrm{M})$ at a perfusate insulin concentration of $100 \mu \mathrm{U} / \mathrm{ml}$. Perfusate flow was $9 \mathrm{ml} / \mathrm{min}$ at rest and $15 \mathrm{ml} / \mathrm{min}$ during electrical stimulation. See Methods for further details. 
Table II. Effect of Caffeine on the Concentration of cAMP ( $\mu \mathrm{mol} / \mathrm{g}$ per ww) in Skeletal Muscle

\begin{tabular}{|c|c|c|c|c|c|c|}
\hline \multirow[b]{2}{*}{ Group } & \multicolumn{2}{|c|}{ Gastrocnemius white } & \multicolumn{2}{|c|}{ Gastrocnemius red } & \multicolumn{2}{|c|}{ Soleus } \\
\hline & Rest & Contractions & Rest & Contractions & Rest & Contraction: \\
\hline Control & $177 \pm 18$ & $113 \pm 18$ & $135 \pm 19$ & $148 \pm 14$ & $174 \pm 22$ & $248 \pm 31$ \\
\hline Caffeine & $171 \pm 15$ & $105 \pm 18$ & $150+21$ & $181+31$ & $207 \pm 31$ & $250 \pm 18$ \\
\hline
\end{tabular}

Values are mean $\pm \mathrm{SE}$ of 10 observations. Hindquarters were perfused in the absence or in the presence of $77 \mu \mathrm{M}$ caffeine at a perfusate insulin concentration of $100 \mu \mathrm{U} / \mathrm{ml}$. Muscle cAMP content was determined in fast-twitch white, fast-twitch red, and slow-twitch red muscle fibers at rest and after 30 min of supramaximal electrical stimulation. See Methods for further details.

$81 \pm 1.3 \mu \mathrm{mol} / \mathrm{g}$ per h $(n=133)$ after $15 \mathrm{~min}$ of electrical stimulation. Muscle tension was on the average $823 \pm 6 \mathrm{~g}(n=154)$ at the onset and $472 \pm 6 \mathrm{~g}(n=154)$ at the end of the 30-min stimulation period. Mean perfusion pressures were $56 \pm 1$ $\mathrm{mmHg}(n=200)$ in resting hindlimbs perfused at a flow of 9 $\mathrm{ml} / \mathrm{min}, 80 \pm 1 \mathrm{mmHg}(n=88)$ in unstimulated hindlimbs perfused at a flow of $15 \mathrm{ml} / \mathrm{min}$ (protocol 3), and $82 \pm 1 \mathrm{mmHg}$ $(n=154)$ after $15 \mathrm{~min}$ of electrical stimulation (protocols 1 and 2).

\section{Discussion}

Insulin and contractions are the major physiological stimulatory agents of the glucose transport system in skeletal muscle. Research over the last decade has elucidated some of the cellular and molecular mechanisms via which insulin and contractions each stimulate muscle glucose transport (33). However, today the precise nature of the interaction of both stimuli in regulating glucose transport rate in muscle is still a matter of debate. There is no doubt that contractions per se can markedly enhance muscle glucose transport, even in total absence of insulin $(34,35)$. Still, however, when muscle is exposed to insulin during contractile activity, the hormone may play an important role in modulating the contraction-induced increase in muscle glucose transport rate. Recent data in perfused rat hindquarters ${ }^{2}$ and in exercising men $(12,13)$, dogs $(14,16)$, and rats (15) in vivo indeed suggest that full stimulation of muscle glucose uptake by contractions requires simultaneous exposure of the muscle to insulin. Little is known, however, on the mechanism by which insulin modulates stimulation of muscle glucose uptake and transport by contractions. The present study was undertaken to explore the role of adenosine receptors in this regulatory process. The data show the important role of $\mathrm{A} 1$ receptors in stimulating the uptake and transport of glucose via insulin in contracting skeletal muscle. This modulation of glucose transport via adenosine receptors probably is a major underlying mechanism explaining the presently and previously observed synergistic regulation (12-16) of muscle glucose transport via insulin and contractions.

During high intensity muscle contractions, ATP is rapidly degraded, leading to enhanced intracellular production of AMP and adenosine, via activation of the adenylate kinase and 5 ' nucleotidase enzymes, respectively. The adenosine formed in the sarcoplasm is released into the interstitial space, where it may act as a local hormone by binding to adenosine receptors present on the cell surface of adjacent cells. Accordingly, hyperemia in active muscle during exercise, at least in muscle primarily composed of slow-oxidative fibers, probably is partly caused by arteriolar vasodilation caused by stimulation of local vascular adenosine receptors (21). The present data provide evidence that besides this potential function in vasomotor regulation, adenosine receptors fulfill at least one other important function in contracting muscle, namely the regulation of insulin action. The findings demonstrate clearly the importance of adenosine receptor activation for insulin to be able to exert its stimulatory action on glucose transport in muscle subjected to contractile activity. This regulatory role of adenosine receptors is restricted to muscle during contractions and does not appear in muscle at rest. In the present study, over the different subgroups of rats studied and hindquarter perfusion protocols (protocols 1-3) used, adenosine receptor antagonism had no significant effect on the rate of glucose uptake in resting hindquarters. Also, when data from the subgroups were pooled (caffeine and CPDPX vs control, $n=146$ ), no significant effect of adenosine receptor antagonism in resting hindquarters was found $(P=0.15)$. In contrast, when muscles were made to contract by electrical stimulation of the sciatic nerve, the increase in hindlimb glucose uptake from rest to contractions was markedly reduced by adenosine receptor antagonism, either with caffeine or CPDPX (Fig. 3). The observations provide evidence that this inhibitory effect was caused by inhibition of a mechanism that augments the insulin effect on muscle glucose transport and is only operative in muscle during contractions. (a) As shown in Fig. 1, the inhibitory effect of caffeine on the contraction-induced increase in muscle glucose uptake was dependent on the presence of insulin in the perfusate mix. The effect was fully reproducable by CPDPX (Fig. 2), which proves adenosine receptors of the Al subtype to be responsible for this inhibition observed. (b) Caffeine inhibited 3-O-methylglucose uptake, a measure of membrane glucose transport, in contracting muscle perfused with insulin. In fact, the degree of inhibition was positively related to the relative sensitivity of the distinct fiber types to insulin $(36,37)$ because inhibition of muscle glucose transport was most pronounced in slow-twitch red muscle fibers $(-42 \%)$, less in fast-twitch red $(-13 \%, \mathrm{NS})$, and absent in fast-twitch white muscle fibers (Fig. 4). (c) The data clearly show adenosine receptor antagonism not to affect the mechanisms via which insulin stimulates glucose uptake in resting muscle because insulin increased the rate of glucose uptake to the same extent in resting hindquarters perfused with and without caffeine (Fig. 1). (d) Adenosine receptor antagonism did not alter stimulation of muscle glucose uptake by contractions per se, since in the absence of insulin the increase in hindlimb glucose uptake from rest to contractions was identical in caffeine and control rats (Fig. 1). (e) The findings exclude adenosine receptors to modulate muscle glucose uptake via a direct effect on the glucose transport system per se. If such a mechanism existed, adenosine receptor 
antagonism would be expected to decrease the rate of glucose transport in all three fiber types and the rate of muscle glucose uptake in the presence and absence of insulin, which did not occur in the present studies. $(f)$ It is worthwhile mentioning that neither caffeine nor CPDPX affected perfusion pressures at rest or during electrical stimulation, indicating unaltered vascular resistance of the hindlimb. This is in apparent contrast with the prevailing opinion of adenosine being a potent local vasodilator (21). However, such an effect is unlikely to occur in the isolated perfused rat hindquarter preparation, which is characterized by a state of major vasodilation because of the absence of $\alpha$-vasoconstrictor tone. Therefore, it is unlikely that the observed effects of caffeine and CPDPX on insulin-stimulated glucose uptake and transport were caused by redistribution of blood flow within the hindlimb.

The data clearly demonstrate adenosine receptor antagonism to inhibit the increase in muscle glucose uptake at the onset of muscle contractions (Fig. 3). One must, however, consider the fact that the increase in muscle glucose uptake observed upon the start of electrical stimulation reflects the combined effect of initiating muscle contractions and concomitantly increasing perfusate flow. Recent experiments in our laboratory have demonstrated that both of these processes are subject to stimulation by insulin. ${ }^{2}$ Thus, adenosine receptor antagonism may have interfered with either or both of these insulin-regulated mechanisms operating at the onset of muscle contractions. However, the present observations suggest that adenosine receptors specifically modulate the mechanism underlying contraction-induced activation of the muscle glucose transport system with no apparent effect on the mechanism by which flow increases muscle glucose uptake because CPDPX inhibited the increment in muscle glucose uptake in contracting muscle perfused, even in the absence of an increase in perfusate flow (Fig. 5). In contrast, the increase in muscle glucose uptake produced by increasing the flow of perfusate in the absence of muscle contractions, was similar in hindquarters perfused with and without caffeine present in the perfusion mix. However, if it is true that insulin has a specific role in regulating glucose transport in contracting muscle, as suggested by the present data, the effect of increasing the flow of perfusate containing insulin in a resting muscle, may not fully reproduce its effect in a contracting muscle. Still, however, the above observations provide additional evidence in support of our hypothesis regarding the specific role of insulin in muscle during contractile activity. Furthermore, two studies in dogs in vivo have shown adenosine to increase insulin-stimulated glucose uptake in myocardium $(26,27)$, supporting our findings of a stimulatory action of adenosine on insulin-stimulated glucose uptake in striated muscle during contractile activity.

As shown in Figs. 1 and 2, neither caffeine nor CPDPX altered glucose uptake rate in unstimulated hindquarters, even with insulin added to the perfusate. This observation, however, does not exclude adenosine receptors to regulate insulin-mediated glucose uptake in muscle at rest. The low rates of adenosine release from well-oxygenated muscles in the resting state, in contrast to muscle during electrical stimulation $(21,22,38)$, may be insufficient to cause significant adenosine receptor activation in a resting hindlimb preparation. Therefore, we studied the effect of $\mathrm{Al}$ receptor agonism on glucose uptake in hindquarters perfused with insulin in the perfusion mix. As shown in Table I, CPA, an adenosine analogue with as great an affinity for A1 receptors than naturally occurring adenosine (32), when added to the perfusate in a concentration exceeding normal physiological plasma adenosine concentrations by at least a factor 3 (39), did not affect glucose uptake in resting hindlimbs. This provides additional support for our contention that the role of adenosine receptors in stimulating insulin action in muscle is restricted to muscle in the contractile state and does not occur in muscle at rest. These findings are in contrast with earlier observations in unstimulated incubated soleus strips $(19,20,40-42)$, which have demonstrated A1 receptor stimulation to inhibit insulin action. The reason for this discrepancy is unclear. However, incubated muscle is a poorer model of resting muscle than perfused muscle, since it is removed from the host and has no circulation. Thus, for instance, the rate of glycolysis in the absence of insulin is $\sim 8 \mu \mathrm{mol} / \mathrm{g}$ per $\mathrm{h}$ in incubated muscle $(20,40)$, whereas it is only $2 \mu \mathrm{mol} / \mathrm{g}$ per h in perfused muscle (43). This suggests that "resting" incubated muscle is, in fact, in an altered metabolic state not comparable to rest. Moreover, in line with our observations, studies on adipocytes have consistently shown adenosine to facilitate a variety of insulin-sensitive processes, including glucose uptake, transport, and oxidation (23-25).

The precise interaction of insulin and contractions in regulating glucose uptake and transport in contracting muscle is still largely unknown. Whereas early studies in this area have indicated that insulin is not necessary for contractions to increase glucose transport $(34,35)$, more recent studies (12-16), including the present one, indicate that insulin augments the response of muscle glucose uptake to contractions. As shown in Fig. 1, glucose uptake rate during contractions in control hindquarters perfused with insulin was, on the average, about twice as high as in control hindquarters perfused with no insulin added to the perfusion mix. This difference was $\sim 60 \%$ because of the difference in glucose uptake rate present in hindquarters already at rest, and in addition, because of a $40 \%$ greater increase in glucose uptake rate induced by a given degree of contractile activity in hindlimbs perfused with insulin. Thus, the magnitude of the increase in muscle glucose uptake produced by muscle contractions is clearly enhanced by insulin. This stimulatory action of insulin, which seems to be mainly (if not entirely) responsible for the synergistic regulation of glucose uptake in skeletal muscle by insulin and by contractions is, as discussed earlier, modulated via adenosine receptors. Additional evidence for such a concept comes from comparison of estimated vs measured rates of glucose uptake in contracting muscle. If one assumes insulin and contractions to independently but additively stimulate muscle glucose transport, the total rate of glucose uptake measured in muscle that has been electrically stimulated to contract during exposure to insulin must be similar to the magnitude of the stimulatory action of contractions added to the rate of glucose uptake in resting muscle. The latter in turn is the resultant of basal glu-

3. Basal glucose uptake was measured in resting hindlimbs perfused at a flow of $9 \mathrm{ml} / \mathrm{min}$ with no insulin added to the perfusate (protocol $1 ; n$ $=14$ ). Insulin-stimulated glucose uptake was calculated as glucose uptake measured in resting hindlimbs perfused at an insulin concentration of $100 \mu \mathrm{U} / \mathrm{ml}$ and at a flow of $9 \mathrm{ml} / \mathrm{min}$ (protocols 1 and 3; $n$ $=51$ ), minus basal glucose uptake. Flow-stimulated glucose uptake was measured in resting hindlimbs perfused with $100 \mu \mathrm{U} / \mathrm{ml}$ insulin added to the perfusate, and in which perfusate flow was increased from 9 to $15 \mathrm{ml} / \mathrm{min}$ for a period of $5 \mathrm{~min}$ ( protocol 3; $n=29$ ). Contractionstimulated glucose uptake was calculated as the difference between 


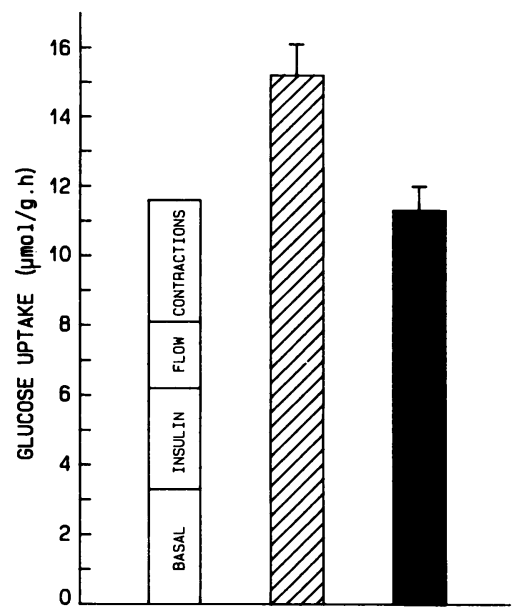

Figure 6. Estimated vs measured rates of muscle glucose uptake after 5 min of contractions. Open bar, glucose uptake rate calculated ${ }^{3}$ as the sum of the stimulatory actions of insulin, contractions, and flow, added to basal glucose uptake rate; hatched and solid bars, glucose uptake rate measured after 5 min of contractions (data are taken from Fig. 1; mean \pm SE are given) in hindlimbs perfused with perfusate containing $100 \mu \mathrm{U} / \mathrm{ml}$

of insulin at a flow of $9 \mathrm{ml} / \mathrm{min}$ before and $15 \mathrm{ml} / \mathrm{min}$ during electrically induced muscle contractions in the control and caffeine groups, respectively.

cose uptake ${ }^{3}$ plus an increase caused by insulin. If onset of contractions is accompanied by an increase in muscle perfusion, the increase in flow will cause a further increment in glucose uptake rate. ${ }^{2}$ Following this line of reasoning, as shown in Fig. 6, the estimated rate of glucose uptake after 5 min of electrical stimulation at increased flow of perfusate containing $100 \mu \mathrm{U} / \mathrm{ml}$ insulin was calculated to be $11.6 \mu \mathrm{mol} / \mathrm{g}$ per $\mathrm{h}$. Interestingly, the rate of glucose uptake actually measured was $\sim 30 \%$ higher $(15.2 \pm 0.9 \mu \mathrm{mol} / \mathrm{g}$ per $\mathrm{h})$, which indicates that the stimulatory action of contractions, insulin, and flow on glucose uptake in muscle is synergistic in nature. The fact that caffeine fully reversed the synergistic effect of insulin and contractions on muscle glucose uptake proves that adenosine receptor-mediated modulation of insulin action in muscle during contractions is indeed responsible for this synergistic mode of regulation (Fig. 6).

The present findings in perfused hindlimbs, together with previous observations in exercising rats $(15)$, dogs $(14,16)$, and humans $(12,13)$, unanimously demonstrate insulin and contractions to act as synergistic stimuli of glucose uptake. This effect is mainly expressed in oxidative muscle fibers $(15,35$, and the present study), and may fade when stimulation of glucose uptake by contractions is added to maximal stimulation by insulin (reference 13 and Hespel, P., L. Vergauwen, K. Vandenberghe, and E. A. Richter, manuscript submitted for publication). Several mechanisms may explain the above observations. (a) At supramaximal insulin concentration, the rate-limiting step of muscle glucose uptake may shift from transport to disposal $(44,45)$. Such a shift is likely to be accelerated by contractions, via a further activation of muscle glucose transport rate on the one hand, and via activation of glycogenolysis on the other hand. $(b)$ Slow oxidative muscle fibers are characterized by the highest rates of adenosine production and release $(21,22,38)$, which, in view of the present findings, is likely to

glucose uptake measured before and after 5 min of electrical stimulation in hindlimbs perfused with no insulin added to the perfusion mix at a constant flow of $15 \mathrm{ml} / \mathrm{min}$ (data from Hespel, P., L. Vergauwen, K. Vandenberghe, and E. A. Richter, manuscript submitted for publication, data obtained according to the conditions described under protocol $2 ; n=12$ ). facilitate synergistic stimulation of muscle glucose uptake by insulin and by contractions. (c) As mentioned earlier, oxidative muscle fibers exhibit the highest degree of sensitivity to insulin $(36,37)$, which probably makes them more susceptible to synergism than other muscle fiber types.

The adenosine receptor-mediated stimulation of insulin action in contracting muscle, as clearly demonstrated by the present study, at least partially provides the explanation for the divergent modes of gluçose uptake regulation occurring during and after muscle contractions. Thus, the stimulation of adenosine receptors by adenosine is probably extremely short lived because of rapid degradation of the adenosine released into the interstitial space by virtue of the action of adenosine deaminase. The extracellular half-life of adenosine indeed has been reported to be only of a few seconds (46). Since insulin action in muscle is only affected by adenosine during contractions, our data then also indicate that postexercise observations on insulin action in skeletal muscle may only partially, if at all, apply to muscle in the contractile state.

Caffeine was used as a tool for the study of adenosine receptor function in regulating glucose uptake and transport in resting and contracting skeletal muscle. Caffeine is one of the oldest and still most used "drugs" in society. It is, therefore, worthwhile mentioning that oral intake of a high dose of caffeine, a common practice in professional endurance type athletes (47), may elevate plasma caffeine concentration to values $>15 \mu \mathrm{g} /$ $\mathrm{ml}$ (48), which is similar to the concentration used in the present hindquarter perfusion experiments. At this concentration, caffeine exerts its physiological effects merely, if not entirely, via inhibition of cellular adenosine receptors (49). The potency of caffeine to stimulate sarcoplasmic reticulum calcium release, as well as to inhibit the phosphodiesterase enzyme, becomes apparent at much higher concentrations of caffeine only, which are toxic or even lethal in vivo (49). The precise cellular process that links adenosine receptor stimulation with enhanced insulin action on muscle glucose transport during contractions remains to be elucidated. Cyclic AMP, a wellknown A1 receptor effector, may be involved in this regulation, since this intracellular messenger is known to activate cAMPdependent protein kinase. The latter has been suggested to phosphorylate the insulin receptor, inhibit its tyrosine kinase activity, and thus induce insulin resistance (50). However, caffeine had no effect on intracellular cAMP (Table II), which argues against its involvement in inhibiting insulin action in contracting muscle. Future studies will have to elucidate the cascade of intracellular events linking adenosine receptor stimulation to insulin action in contracting skeletal muscle, with special attention focused on the role of phospholipase $C$ and $\mathrm{Ca}^{2+}$, two other potential intracellular effectors of adenosine receptors $(51)$.

In conclusion, the data presented in this study provide clear evidence for the existence of an A1 receptor-dependent mechanism of action, via which insulin specifically stimulates glucose transport in muscle subjected to contractile activity. It is suggested that this mechanism is responsible for the synergistic nature of glucose uptake stimulation by insulin and contractions occurring in muscle during contractions.

\section{Acknowledgments}

We thank Betina Bolmgreen for providing skilled technical assistance.

This study was supported by grants from the Belgian National Research Council "Fonds voor Geneeskundig Wetenschappelijk Onder- 
zoek (FGWO)," grant 9.0031.90; the "Onderzoeksraad K.U. Leuven", grant OT/91/34; and the Danish National Sciences Research Council, grant 11-0082-1.

\section{References}

1. Baron, A. D., G. Brechtel, P. Wallace, and S. V. Edelman. 1988. Rates and tissue sites of non-insulin- and insulin-mediated glucose uptake in humans. $\mathrm{Am}$. J. Physiol. 255:E769-774.

2. Holloszy, J. O., and H. T. Narahara. 1967. Enhanced permeability to sugar associated with muscle contraction. Studies of the role of calcium. J. Gen. Phys iol. 50:551-562.

3. Burn, J. H., and H. H. Dale. 1924. On the location and nature of the action of insulin. J. Physiol. 59:164-192.

4. Wardzala, L. J., and B. Jeanrenaud. 1983. Identification of D-glucose inhibitable cytochalasin $B$ binding site as the glucose transporter in rat diaphragm plasma and microsomal membranes. Biochim. Biophys. Acta. 730:49-56.

5. Klip, A., T. Ramlal, D. A. Young, and J. O. Holloszy. 1987. Insulin-induced translocation of glucose transporters in rat hindlimb muscles. FEBS (Fed. Eur. Biochem. Soc.) Lett. 224:224-230.

6. Hirshman, M. F., H. Wallberg-Henriksson, L. J. Wardzala, E. D. Horton, and E. S. Horton. 1988. Acute exercise increases the number of plasma membrane glucose transporters in rat skeletal muscle. FEBS (Fed. Eur. Biochem. Soc.) Lett. 238:235-239.

7. Sternlicht, E., R. J. Barnard, and G. K. Grimditch. 1988. Mechanism of insulin action on glucose transport in rat skeletal muscle. Am. J. Physiol. 254:E633-E638.

8. King, P. A., M. F. Hirshman, E. D. Horton, and E. S. Horton. 1989. Glucose transport in skeletal muscle membrane vesicles from control and exercised rats. Am. J. Physiol. 257:C1128-C1134.

9. Douen, A. G., T. Ramlal, A. Klip, D. A. Young, G. D. Cartee, and J. O. Holloszy. 1989. Exercise-induced increase in glucose transporters in plasma membranes of rat skeletal muscle. Endocrinology. 124:449-454.

10. Ingle, D. J., J. E. Nezamis, and E. H. Morley. 1951. Work output and blood glucose values in severely diabetic rats with and without insulin. Am. J. Physiol. 165:469-472.

11. Berger, M., S. Hagg and N. B. Ruderman. 1975. Glucose metabolism in perfused skeletal muscle. Interaction of insulin and exercise on glucose uptake. Biochem. J. 146:231-236.

12. DeFronzo, R. A., E. Ferrannini, Y. Sato, and P. Felig. 1981. Synergistic interaction between exercise and insulin on peripheral glucose uptake. J. Clin. Invest. 68:1468-1474.

13. Wasserman, D. H., R. J. Geer, D. E. Rice, D. Bracy, P. J. Flakoll, L. L. Brown, J. O. Hill, and N. N. Abumrad. 1991. Interaction of exercise and insulin in humans. Am. J. Physiol. 260:E37-E45.

14. Wasserman, D. H., T. Mohr, P. Kelly, D. Brooks Lacey, and D. Bracy. 1992. Impact of insulin deficiency on glucose fluxes and muscle glucose metabolism during exercise. Diabetes. 41:1229-1238.

15. Turinsky, J. 1987. Glucose and amino acid uptake by exercising muscles in vivo: effect of insulin, fiber population and denervation. Endocrinology. 121:528-535.

16. Vranic, M., R. Kawamori, S. Pec, N. Kovacevic, and G. A. Wrenshall. 1976. The essentiality of insulin and the role of glucagon in regulating glucose utilisation and production during strenuous exercise in dogs. J. Clin. Invest. 57:245-255.

17. Wallberg-Henriksson, H., and J. R. Zierath. 1992. Interaction of insulin and skeletal muscle contraction on glucose uptake. In Diabetes Mellitus and Exercise. J. T. Devlin, E. S. Horton, and M. Vranic, editors. Smith-Gordon/Nishimura, London. pp. 69-79.

18. Goodyear, L. J. 1992. Effects of exercise and insulin on the glucose transport system in skeletal muscle. In Diabetes Mellitus and Exercise. J. T. Devlin, E. S. Horton, and M. Vranic, editors. Smith-Gordon/Nishimura, London. pp. 1324.

19. Leighton, B., F. J. Lozeman, I. G. Vlachonikolis, R. J. A. Challis, J. A Pitcher, and E. A. Newsholme. 1988. Effects of adenosine deaminase on the sensitivity of glucose transport, glycolysis and glycogen synthesis to insulin in muscles of the rat. Int. J. Biochem. 20:23-27.

20. Challis, R. A. J., S. J. Richards, and L. Budohoski. 1992. Characterization of the adenosine receptor modulating insulin action in rat skeletal muscle. Eur. $J$. Pharmacol. 226:121-128.

21. Schwartz, L. M., and J. E. McKenzie. 1990. Adenosine and active hyperemia in soleus and gracilis muscle of cats. Am. J. Physiol. 259:H1295-H1304.

22. Achike, F. I., and H. J. Ballard. 1993. Influence of stimulation parameters on the release of adenosine, lactate and $\mathrm{CO}_{2}$ from contracting dog gracilis muscle. J. Physiol. 463:107-121.
23. Joost, H. G., and H. J. Steinfelder. 1983. Effects of theophylline on insulin receptors and insulin action in the adipocyte. Mol. Cell. Biochem. 57:177-183.

24. Steinfelder, H. J., and S. Pethö-Schramm. 1990. Methylxantines inhibit glucose transport in rat adipocytes by two independent mechanisms. Biochem. Pharmacol. 40:1154-1157.

25. Taylor, W. M., and M. L. Halperin. 1979. Stimulation of glucose transport in rat adipocytes by insulin, adenosine, nicotinic acid and hydrogen peroxide. Biochem. J. 178:381-389.

26. Law, W. R., M. P. McLane, and R. M. Raymond. 1988. Adenosine is required for myocardial insulin responsiveness in vivo. Diabetes. 37:842-845.

27. Law, W. R., and R. M. Raymond. 1988. Adenosine potentiates insulinstimulated myocardial glucose uptake in vivo. Am. J. Physiol. 254:H970-H975.

28. Ruderman, N. B., C. R. S. Houghton, and R. Hems. 1971. Evaluation of the isolated perfused rat hindquarter for the study of muscle metabolism. Biochem. J. 124:639-651.

29. Goodman, M. N., N. B. Ruderman, and T. T. Aoki. 1978. Glucose and amino acid metabolism in perfused skeletal muscle. Effect of dichloroacetate. Diabetes. 27:1065-1074.

30. Richter, E. A., N. B. Ruderman, M. Gavras, E. R. Belur, and H. Galbo. 1982. Muscle glycogenolysis during exercise. Dual control by epinephrine and contractions. Am. J. Physiol. 242:E25-E32.

31. Hickson, R. C., W. W. Heusner, W. D. Van Huss, J. F. Taylor, and R. E. Carrow. 1976. Effects of an anabolic steroid and sprint training on selected histochemical and morphological observations in rat skeletal muscle types. Eur. $J$ Appl. Physiol. 35:251-259.

32. Bruns, R. F., J. H. Fergus, E. W. Badger, J. A. Bristol, L. A. Santay, J. D. Hartman, S. J. Hays, and C. C. Huang. 1987. Binding of the Al-selective adenosine antagonist 8-cyclopentyl-1,3-dipropylxantine to rat brain membranes. Naunyn-Schmiedebergs Arch. Pharmakol. 335:59-63.

33. Klip, A., and M. R. Pacquet. 1990. Glucose transport and glucose transporters and their metabolic regulation. Diabetes Care. 13:228-243.

34. Ploug, T., H. Galbo, and E. A. Richter. 1984. Increased muscle glucose uptake during contractions: no need for insulin. Am. J. Physiol. 247:E726-E731.

35. Nesher, R., I. E. Karl, and D. M. Kipnis. 1985. Dissociation of effects of insulin and contraction on glucose transport in rat epitrochlearis muscle. Am. J. Physiol. 249:C226-C232.

36. Bonen, A., M. H. Tan, and W. M. Watson-Wright. 1981. Insulin binding and glucose uptake differences in rodent skeletal muscles. Diabetes. 30:702-704

37. James, D. E., A. B. Jenkins, and E. W. Kraegen. 1985. Heterogeneity of insulin action in individual muscles in vivo. Euglycemic clamp studies in rats. Am. J. Physiol. 248:E567-E574.

38. Bockman, E. L., and McKenzie, J. E. 1983. Tissue adenosine content in active soleus and gracilis muscles of cats. Am. J. Physiol. 244:H552-H559.

39. Arch, J. R. S., and E. A. Newsholme. 1978. The control of the metabolism and the hormonal role of adenosine. Essays Biochem. 14:82-123.

40. Espinal, J., J. R. A. Challis, and E. A. Newsholme. 1983. Effect of adenosine deaminase and an adenosine analogue on insulin-sensitivity in soleus muscle of the rat. FEBS (Fed. Eur. Biochem. Soc.) Lett. 158:103-106.

41. Budohoski, L., J. R. A. Challis, B. McManus, and E. A. Newsholme. 1984a. Effects of analogues of adenosine and methylxantines on insulin-sensitivity in soleus muscle of the rat. FEBS (Fed. Eur. Biochem. Soc.) Lett. 167:1-4.

42. Budohoski, L., J. R. A. Challis, F. J. Lozeman, B. McManus, and E. A. Newsholme. 1984b. Increased insulin-sensitivity in soleus muscle from cold-exposed rats. Reversal by an adenosine receptor agonist. FEBS (Fed. Eur. Biochem. Soc.) Lett. 175:402-406.

43. Berger, M., S. A. Hagg, M. N. Goodman, and N. B. Ruderman. 1976. Glucose metabolism in perfused skeletal muscle. Biochem. J. 158:191-202.

44. Kubo, K., and J. E. Foley. 1986. Rate-limiting steps for insulin-mediated glucose uptake into perfused rat hindlimb. Am. J. Physiol. 250:E100-E102.

45. Furler, S. M., A. B. Jenkins, L. H. Storlien, and E. W. Kraegen. 1991. In vivo location of the rate-limiting step of hexose uptake in muscle and brain tissue of rats. Am. J. Physiol. 261:E337-E347.

46. Bruns, R. F. 1990. Adenosine receptors: roles and pharmacology. Ann. NY Acad. of Sci. 603:211-226.

47. Delbeke, F. T., and M. Debackere. 1984. Caffeine: use and abuse in sports. Int. J. Sports Med. 5:179-182.

48. Robertson, D., D. Wade, R. Workman, R. L. Woosley, and J. O. Oates. 1981. Tolerance to humoral and hemodynamic effects of caffeine in man. J. Clin. Invest. 67:1111-1117.

49. Fredholm, B. B. 1985 . On the mechanism of action of theophylline and caffeine. Acta Med. Scand. 217:149-153.

50. Zick, Y. 1989. The insulin receptor. Structure and function. Crit. Rev. Biochem. Mol. Biol. 24:217-269.

51. Olsson, R. A., and J. D. Pearson. 1990. Cardiovascular purinoceptors. Physiol. Rev. 70:761-845. 